Research Article

http://dx.doi.org/10.17784/mtprehabjournal.2014.12.169

\title{
The myofascial release and the treatment of tension headache induced by trigger points.
}

\author{
A liberação miofascial e o tratamento de cefaleia tensional induzida por pontos-gatilho.
}

Rayssilane Cardoso de Sousa(1), Ludmilla Karen Brandão Lima de Matos ${ }^{(2)}$.

Faculdade Integral Diferencial (FACID Devry), Teresina (PI), Brazil.

\begin{abstract}
Introduction: The presence of trigger points (TP) characterize the myofascial pain syndrome, which is associated with the Tension-Type Headaches (THH) when the TP's are located in the muscles of the head and neck, whose pattern of referred pain is propagated to certain regions of the head. In this context, the myofascial release (MR) has fundamental techniques for disabling TP's and its symptoms. Objective: To verify the effects of myofascial release (MR) in the treatment of TTH induced to TP's. Method: This study received approval from the Human Research Ethics Committee of a private college in Teresina-PI (No. 193 142). It is a series of cases report, of analytical nature with quantitative and qualitative approach. The sample was constituted by nine subjects with $42.67 \pm 6.84$ years, selected through a selecting form. They were evaluated before and after the treatment by means of an evaluation form (weight, height, goniometry cervical spine and visual analog pain scale - VAS) and the SF-36 Questionnaires. Was applied a protocol of physical therapy treatment with MR techniques, two times a week, 16 sessions. Analyzed variables: intensity of pain, range of movement (ROM) of the cervical spine and quality of life. Data were analyzed using parametric test " $t$ " of Student, with significance level of $p \leq 0.05$. Results: Data were reported in tables and graphs showing significant results. There was an increase of cervical spine ROM, reduced intensity of pain (VAS) and improves the quality of life of participants (SF-36 Questionnaire). Conclusion: The conclusion is that the protocol of physical therapy treatment with MR techniques showed significant results in the treatment of $\mathrm{TTH}$.
\end{abstract}

Keywords: Tension type headaches. Trigger points. Physical Therapy Modalities

\section{Resumo}

Introdução: A presença de pontos-gatilho (PG's) caracteriza a Síndrome Dolorosa Miofascial, a qual está associada à Cefaleia do Tipo Tensional (CTT), quando os PG's estão situados nos músculos da cabeça e pescoço, cujo padrão de dor referida é propagado para determinadas regiões da cabeça. Nesse contexto, a Liberação Miosfacial (LM) possui técnicas fundamentais para a desativação de PG's e seus sintomas. Objetivo: Verificar os efeitos da liberação miofascial (LM) no tratamento da CTT induzida por PG's. Método: Esta pesquisa foi submetida ao CEP de uma faculdade particular em Teresina-PI (no 193.142). É uma série de estudo de caso, de natureza analítica, com abordagem quanti-quali.

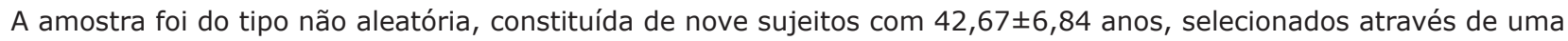
ficha de triagem. Os mesmos foram avaliados, antes e após o tratamento, por meio de uma ficha de avaliação (peso, altura, goniometria da coluna cervical e escala visual analógica da dor - EVA) e do Questionário de SF-36. Foi aplicado um protocolo de tratamento fisioterapêutico com técnicas de LM, duas vezes/semana, 16 atendimentos. Variáveis analisadas: intensidade da dor, amplitude de movimento (ADM) da coluna cervical e qualidade de vida. Os dados foram analisados através do teste paramétrico " $t$ " de Student, com nível de significância de $p \leq 0,05$. Resultados: Os dados foram expostos em tabelas e gráficos revelando resultados significativos. Houve aumento da ADM da coluna cervical, redução da intensidade da dor (EVA), além de melhora da qualidade de vida das participantes (Questionário de Qualidade de Vida SF-36). Conclusão: O protocolo de tratamento fisioterapêutico com técnicas LM apresentou resultados significativos no tratamento da CTT.

Palavras-chave: Cefaleia do Tipo Tensional, Pontos-gatilho, Modalidades de Fisioterapia.

\section{Received: 27 November 2013. Accepted: 12 March 2014. Published: 30 March 2014.}

1. Physical Therapy School and scholarship in scientific initiation, Faculdade Integral Diferencial (FACID Devry), Teresina (PI), Brazil. 2. PT, professor and guiding of scientific initiation, Faculdade Integral Diferencial (FACID Devry), Teresina (PI), Brazil.

\section{Corresponding Author:}

Rayssilane Cardoso de Sousa, Quadra 114, Casa 08, Dirceu Arcoverde 1, Phone: (086) 3236-2875, Mobile: (086) 9495-5331, (086) 9901-9045, email: rayssilane14@hotmail.com 


\section{BACKGROUND}

The presence of trigger points characterize the Myofascial Pain Syndrome (MPS), which is a neuromuscular disorder characterized by sensitive regions in tense muscle band, which takes the muscles to a state of shortening or contracture, with an increase of the tone and rigidity which could be the cause or be associated to the Tension-Type Headache (TTH) - one of the most commons types of secondary pain of TP's when they were situated in muscles of head and neck which produces the same pattern of related pain disseminates to different regions of the skull, therefore, frequently associated to a myofascial component. ${ }^{(1,2,3)}$

The PG's are related to clinical and physical findings such as burning pain or tenderness at the site in the muscle involved, tense muscle band, sensitive and painful nodules, Local spasm, limited range of motion, sleep disorders, among others. Individuals with $\mathrm{TH}$ have musculoskeletal disorders in the craniocervical region, which normally occur with pericranial muscle tenderness, increased cervical muscle tone, abnormal mobility of the neck, forward head, trigger points in the muscles of the head and neck disorders and sleep. $(4,5,6,7)$

In addition, the TP's nociception on the myofascial system could initiate headache in different regions of the head, producing a framework of tension headache according to the TP localization and the pattern of referred pain (generally constant and similar to each group, not following the dermatome or radicular standard) principally when situated in muscles trapezius superior part, sternocleidomastoid, sub occipital, splenius capitis and splenius cervicis. ${ }^{(3,8)}$

In this context, the TTH is a painful condition (referred pain in a neuromuscular dysfunction context) principally common at the third decade of life (where the emotion, family and professional problems are more frequently); the localization is generally at frontal and temporal region with occipital component; the pain intensity is light to moderate; a there is a heaviness sensation, pressure, grip and tense band round the neck. Furthermore, the sensibility and the muscle tense are common in cervical region. ${ }^{(9,10)}$

Of the various treatments for MPS, stands out manual therapy and one of the widely used techniques is myofascial release (MR), which is the release of tension in the muscle and fascia, seeking to restore the normality of neuromuscular function, and may provide relief of tension headache in the short and long term, reducing the frequency of episodes, increased range of motion of the cervical spine and lower use of drugs, as it has fundamental techniques for disabling PG's and their symptoms, whereas the $\mathrm{TTH}$ is secondary to thereof. $(3,11,12,13,14)$

This study had the objective to analyze the effects of MR in the treatment of $\mathrm{TTH}$ induced by trigger points and, more specifically, to measure the range of motion of the cervical spine in TTH patients; to verify the decrease of irradiated pain; to analyze the quality of life in patients with tensional pain and to quantify the frequency of tensional pain.

\section{METHODS}

This study was initiated after submission and approval of the Human Research Ethics Committee from a private college (number 193.142). The data were collected after the patients agreed to participate and signed the Instrument of Consent.

The study was sketchy as a series of cases report, with and approach qualitative and quantitative. The data was collected in a clinic school of a private college. The sample was composed by nine subjects who were directed to Physical Therapy service at clinic school.

The inclusion criteria were subjects with $\Pi \mathrm{TH}$, with 35 to 58 years. The volunteer answered a screening established form to verify if they had $\mathrm{TTH}$. The form was elaborated following the literature information about the characteristics of $T \mathrm{TH} .{ }^{(9,10)}$ The exclusion criteria was the subjects who were in physical therapy or pharmacological treatment and the ones who presented any contraindication to MR technique.

Participants were assessed before treatment and after twenty sections, following the assessed form where were collected: weight, height, goniometry of cervical spine and visual analogic scale (VAS). Moreover, the patients answered the SF-36 health survey questionnaire. ${ }^{(15)}$

The protocol of al therapy treatment was applied, totaling 16 sessions, two times a week. The techniques performed was: ischemic compression (deactivation of TP for 90 seconds), ${ }^{(8)}$ myofascial massage (deep slip, direct vibration on the TP, rolling and compression), ${ }^{(16)}$ pompage ( $3 \times 20^{\prime \prime}$ - semispinalis head muscle, trapezius superior part and sternocleidomastoid) $)^{(17)}$ and myofascial stretching ( $3 \times 30^{\prime \prime}$ - upper trapezius muscles part, sternocleidomastoid, sub occipital, splenius capitis and splenius cervicis). (4)

The variables were the pain intensity by VAS, range of movement of the cervical spine measured by goniometry and quality of life by SF-36 health survey questionnaire.

Data were tabulated at Excel 2010. After data collection, they were statistically analyzed by nonparametric test " $t$ " test, with significance level of $p \leq 0.05$.

\section{RESULTS}

The sample was composed by nine female subjects with $42.67 \pm 6.84$ years. Data were organized in tables and graphics and statistically compared nonparametric " $t$ " test, with significance level of $p \leq 0.05$ according to the parameters values obtained at the initial and final evaluation and among physical therapy treatment.

The comparative analysis by the initial and final 
range of movement of cervical spine (Table 1) pointed an increase of range of movement statistically significant to all movements.

The results of the comparison of quality of life before and after applying the physical therapy protocol are presented in table 2. Between initial and final evaluation, the only domains that did not presented significant statistically differences were the role-emotional $(t=0.0518)$ and mental health $(t=0.0548)$.

Regarding pain, according to Visual Analogic Scale (VAS) the pain index, before and after treatment, the Graphic 1 reveal significant results $(p<0.0001 * * *)$, as reduction of the mean of pain intensity $7.33 \pm 0.167$ to $2.56 \pm 0.580$.

\section{DISCUSSION}

To $\mathrm{TTH}$, many times is attributed a non-pharmacological treatment, which have a prophylactic action. (18) Should emphasize the importance of preventive actions in the $\mathrm{TH}$ fighting, as stimulate the adoption of healthy life habits, trying to minimize the indiscriminate administration of drugs, because studies suggested that there are a straight relationship between stress and $\mathrm{TTH}$ in females, what could be related to cyclic flotation of estrogen and progesterone which increase the stress responses. ${ }^{(12,19)}$
The $T \mathrm{TH}$ is one of the most frequent cephalic pains, but still little known about the pathophysiological mechanisms. Often it is associated with myofascial pain being the most common type of pain secondary to PG's in the muscles of the cervical region. It is known that muscle tension in the cervical region, which is quite common in $\mathrm{TH}$, is related to a sustained isometric contraction given to maintain an ergonomically poor pos-

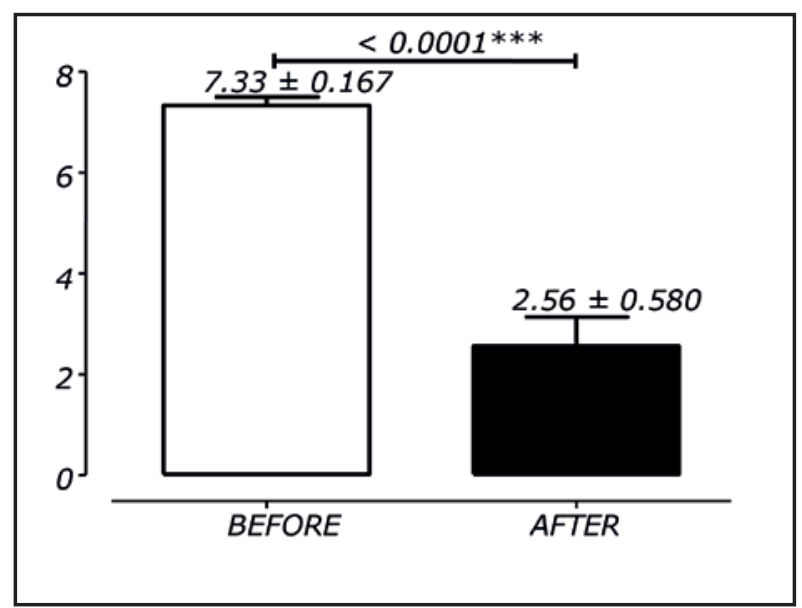

Figure 1. Values of the Visual Analogue Scale scores of patients before and after the application of physical therapy protocol.

Table 1. Movements goniometry of the cervical spine before and after the application of physical therapy protocol. Data presented as mean \pm standard deviation.

\begin{tabular}{|c|c|c|c|c|c|}
\hline \multirow{2}{*}{ Moviment } & \multicolumn{2}{|c|}{ Before } & \multicolumn{2}{|c|}{ After } & \multirow{2}{*}{$\mathbf{P}$} \\
\hline & M & Sd & M & Sd & \\
\hline Flexion & 31.00 & 8.97 & 40.33 & 7.40 & $0.003 * *$ \\
\hline Extension & 33.33 & 6.12 & 43.44 & 7.30 & $0.0008 * * *$ \\
\hline Rot. L. & 58.89 & 15.37 & 75.56 & 8.14 & $0.002 * *$ \\
\hline Rot. R. & 51.11 & 11.40 & 73.67 & 10.71 & $0.0001 * * *$ \\
\hline Lat. L. & 39.44 & 9.22 & 51.67 & 7.91 & $0.001 * * *$ \\
\hline Lat. R. & 39.44 & 12.36 & 51.89 & 6.77 & $0.008 * *$ \\
\hline
\end{tabular}

Subtitle: T, T Student; **Significance In $\mathrm{P}<0.01 ; * * *$ Significance In $\mathrm{P}<0.001$. Source: Original Data.

Table 2. Questionnaire scores of the SF-36 before and after the application of physical therapy protocol.

\begin{tabular}{|c|c|c|c|c|c|}
\hline \multirow{2}{*}{ Domain } & \multicolumn{2}{|c|}{ Before } & \multicolumn{2}{|c|}{ After } & \multirow{2}{*}{$\mathbf{T}$} \\
\hline & M & Sd & M & Sd & \\
\hline Physical Functioning & 76.67 & 17.50 & 89.44 & 11.58 & $0.0189 *$ \\
\hline Role-Physical & 55.56 & 37.03 & 97.22 & 8.33 & $0.005 * *$ \\
\hline Bodily Pain & 47.78 & 8.86 & 71.00 & 19.53 & $0.0022 * *$ \\
\hline General Health & 55.22 & 22.84 & 79.89 & 14.55 & $0.0002 * * *$ \\
\hline Vitality & 58.89 & 19.49 & 75.00 & 15.21 & $0.0149 *$ \\
\hline Social Function & 68.06 & 25.85 & 94.44 & 9.08 & $0.0049 * *$ \\
\hline Role-Emotional & 85.17 & 24.24 & 100.00 & 0.00 & 0.0518 \\
\hline Mental Health & 72.89 & 11.96 & 83.56 & 15.29 & 0.0548 \\
\hline
\end{tabular}


ture, changes in the cervical spine or emotional strains in certain contexts and for a prolonged period, where such tension alters the blood supply and local nutrition and generates a feeling of tense band around the head. $(9,10,11,12,19,20)$

In this context, the TH could be related to a myofascial component and the literature suggest the adoption of non-pharmacological therapies for the treatment. To some authors, the conventional physical therapy shows efficiency in the treatment of this affection, although, there are no physiotherapy protocols defined to this purpose. ${ }^{(19,21)}$

The manual therapy by means of myofasciais techniques had fundamental modalities to deactivate the trigger points and your symptoms and had revealed very effective in $\mathrm{TH}$ resolution. The literature has reported evidences reduction of frequency, intensity and pain duration of $\mathrm{TTH}$, ingest of drugs reduction, moreover the improve of quality of life, revealing to be useful as a supporting or as an isolated therapy effectively in the treatment of this disfunction. ${ }^{(3,19,20,22,23,24)}$

The physiotherapy treatment protocol applied with MR techniques shows significant results in the treatment of TTH in the analyzed variables. Regarding the range of motion of the cervical spine (Table 1 ), the range of motion presented in increased to all movement, suggesting relief of muscles tension/spasm, since stretching of muscle fibers shortened.

In the quality of life analysis (table 2), all domains reveal statistically significant, exception the role-emotional and mental health. Thus, results suggested the importance of the physical therapy performance in the relief of $\mathrm{TTH}$ and beneficial to quality of life. Regarding to role-emotional and mental health, it should be emphasized that a huge oscillation of standard deviation happened, related to the established mean between patients, which directly interfered in the results significance.

Moreover, some participants related, during the anamnesis and among treatment, through many stressful situations that are permanent in them daily routine, being in familiar or professional context with a stronger emotional factor associated. Nevertheless, it was relevant, because the results get closer to the significance level de $p \leq 0.05$ (role-emotional: $t=0.0518$ and mental health: $t=0.0548)$.

Related to pain intensity evaluated by VAS (Graphic 1 ), there was a decrease in average $7.33 \pm 0.167$ to $2.56 \pm 0.580$ in the referred index. The results corroborate with the literature. One research aimed to examine the evolution in six patients with $\mathrm{TTH}$ diagnosis, underwent to a physical treatment of manual therapy protocol (10 sessions with manual cervical traction, stretching muscles bilateral trapezius superior part, scalene, levator scapulae and sternocleidomastoid; spinal mobilization and massage), it was notice that the increase of pain limier by pressure and reduction of pain intensity. ${ }^{(18)}$

In another study to evaluate the efficacy of manual therapy in chronic TTH participants, a randomized clinical trial with 82 participants divided randomly into control group (guidance on lifestyle changes and, if necessary, prescription medications for pain relief was achieved) and the treatment group (cervical and thoracic mobilization exercises and postural correction). In the treatment group compared to the control group, manual therapy was effective in the short and long term to reduce the frequency, intensity of pain and $\mathrm{TH} \mathrm{H}$ quality of life impact. Other parameters such as range of motion, muscle strength and algometry neck flexors show significance only in the short term. ${ }^{(13)}$

\section{CONCLUSION}

The literature suggests the effectiveness of manual therapy in the treatment of tension-type headache. However, there is still no scientific standard as to which techniques should be used, as they are usually presented associated. In this context, one should emphasize the importance of conducting comparative studies and larger samples. In the case of this study, the protocol of physical therapy, developed with myofascial release techniques showed significant results in the treatment of tension-type headache.

\section{REFERENCES}

1. Bigongiari A, Franciulli PM, Souza FA, Mochizuki L, Araujo RC. Análise da Atividade Eletromiográfica de Superfície de Pontos Gatilhos Miofasciais. Rev Bras Reumatol. 2008;48(6):319-324.

2. Guyton AC, Hall JE. Tratado de fisiologia médica. 11. ed. Rio de Janeiro: Elsevier, 2006.

3. Yeng LT, Kaziyama HH, Teixeira MJ. Síndrome dolorosa miofascial. JBA. 2003;3(9):27-43.

4. Kostopoulos D, Rizopoulos K. Pontos-Gatilho miofasciais: teoria, diagnóstico e tratamento. Rio de Janeiro: Guanabara Koogan, 2007.

5. Fernandez-De-Las-Peñas C, Cuadrado ML, Pareja JA. Myofascial trigger points, neck mobility and forward head posture in episodic tension-type headache. Headache. 2007; 47(5): 662-72. 
6. Abboud J, Marchand AA, Sorra K, Descarreaux M. Musculoskeletal physical outcome measures in individuals with tension-type headache: a scoping review. Cephalalgia. 2013; 33(16): 1319-36.

7. Martin-Herrero C, Rodrigues De Souza DP, Alburquerque-Sendín F, Ortega-Santiago R, Fernández-De-Las-Penãs C. Myofascial trigger points, disability and qualit of sleep in patients with chronic tension-type headache: a pilot study. Rev Neurol. 2012; 55(4): 193-9.

8. Simons LS, Travel JG. Dor e disfunção miofascial: manual dos pontos-gatilho volume 1 - parte superior do corpo. Artmed: Porto Alegre, 2005.

9. Nitrini R, Bacheschi LA. A neurologia que todo medico deve saber. 2. ed. São Paulo: Atheneu, 2005.

10. Varjão FM, Jorge JH, Nepelenbroek KH, Alencar Júnior FGP. Cefaleia, tipo tensional. SaudPesq. 2008; 1(2):185191.

11. Silva RD. Influência da liberação miofascial sobre a dor e disfunção cervical. In: IX Amostra Acadêmica. 2011. UNIMEP - Universidade Metodista de Piracicaba. Anais. Piracicaba. 2011.

12. Medeiros AA, Lima BRDA, Siqueira DF. A eficácia da fisioterapia manual na cefaléia tensional: uma revisão sistemática. Rev Ter Man. 2012; 10(47): 100-104.

13. Castien RF, Windt DAWM, Grooten A, Dekker J. Effectiveness of manual therapy compared to usual care by the general practitioner for chronic tension-type headache: design of a randomized clinical trial. Cephalalgia. 2009; 31(2):133-143.

14. Alonso-Blanco C, De-La-Liave-Rincón AI, Fernández-De-Las-Peñas C. Muscle trigger point therapy in tension-type headache. Expert Rev Neurother. 2012; 12(3): 315-22.

15. Mercante JPP, Bernik MA, Zukerman-Guendler V, Zukerman E, Kuczynski E, Peres MFP. Comorbidade psíquica diminui a qualidade de vida de pacientes com enxaqueca crônica. Arq Neuropsiquiatr. 2007; 65(3-B): 880-884.

16. Dixon MW. Massagem miofascial. Rio de Janeiro: Guanabara Koogan, 2007.

17. Bienfait, M. Fáscia e pompage. 4. ed. São Paulo: Summus, 1999.

18. Morelli JGS, Rebelatto JR. A eficácia da terapia manual em indivíduos cefálicos portadores e não portadores de degeneração cervical: análise de 6 casos. Rev Bras Fisioter. 2007; 11(4):325-9.

19. Bernardi MT, Bussadori SK, Fernandes KPS, Biasotto-Gonzalez DA. Correlação entre estresse e cefaleia tensional. Fisioter. Mov. 2008; 21(1):87-93.

20. Amorim ECO, Daher CRM. Efeitos da Terapia Manual no Tratamento de Cefaléia tipo Tensional: Uma Revisão de Literatura. Revista Inspirar. 2010; 2(2):11-8.

21. Santos CMT, Pereira CU, Lima PTMR, Santos EAS, Monteiro JTS. Como diagnosticar e tratar Cefaléia Tensional. Revista Brasileira de Medicina. Moreira Jr. 2007; 112-117.

22. Araújo APS, Almeida CA. Terapia manual versus acupuntura no tratamento da cefaleia: revisão de literatura. SaudPesq. 2009; 2(1):107-13.

23. Bernardo DA, Pinheiro MC, Conegundes LS, Pinto RC, Pinheiro TJS, Pinheiro ACO. Os benefícios da terapia manual em pacientes com diagnóstico de cefaleia do tipo tensional. 2013; 182.

24. Macedo CSG, Cardoso JR, Prado FMLO, Carvalho PG. Eficácia da terapia manual craniana em mulheres com cefaleia. Fisioter Pesq. 2007; 14(2):14-20. 